\title{
Patients' perspectives on acromegaly diagnostic delay: a qualitative study
}

\author{
Jordan Sibeoni 1,2,*, Emilie Manolios ${ }^{2,3, *}$, Laurence Verneuil'2, Philipe Chanson ${ }^{4,5 * *}$ and Anne Revah-Levy ${ }^{1,2 * *}$ \\ ${ }^{1}$ Service Universitaire de Psychiatrie de l'Adolescent, Argenteuil Hospital Centre, Argenteuil, France, ${ }^{2} E C S T R R A$ Team, UMR-1153, \\ Inserm, Paris Diderot University, Sorbonne Paris Cité, France, ${ }^{3}$ Service de Psychologie et Psychiatrie de Liaison et d'Urgences, Hôpital \\ Européen Georges Pompidou AP-HP, Hôpitaux Universitaires Paris Ouest, Paris, France, ${ }^{4}$ Assistance Publique-Hôpitaux de Paris, \\ Hôpital de Bicêtre, Service d'Endocrinologie et des Maladies de la Reproduction, Centre de Référence des Maladies Rares de \\ I'Hypophyse, Le Kremlin Bicêtre, France, and 5 UMR S 1185, Fac Med Paris Sud, Univ Paris-Sud, Université \\ Paris-Saclay, Le Kremlin-Bicêtre, France \\ *(U Sibeoni and E Manolios contributed equally to this work) \\ **(P Chanson and A Revah-Levy contributed equally to this work) \\ Correspondence \\ should be addressed \\ to P Chanson \\ Email \\ philippe.chanson@bct.aphp.fr
}

\begin{abstract}
Context: Acromegaly has a substantial diagnostic delay associated with an increased risk of comorbidities and psychosocial deterioration. Qualitative methods which focus on the ways that individuals understand and relate to what they are experiencing are the best methods for exploring patients' perspectives. To the best of our knowledge, they have not been developed in the context of acromegaly.

Objectives: This study aimed to explore the experience of the diagnostic pathway of patients with acromegaly. Design: We conducted a qualitative study, based on 20 face-to-face unstructured interviews in a third referral Endocrinology center. Participants, purposively selected until data saturation, were patients with acromegaly with diverse disease durations, types of treatment or associated comorbidities. The data were examined by thematic analysis. Results: Our analysis found four themes: (i) what happened for patients before the diagnosis; (ii) what happened after; (iii) the style or type of doctor involved and (iv) patients' suggestions for limiting diagnostic delay. Our findings underlined the direct associations between diagnostic delay and the doctor-patient encounter, and the truly catastrophic experience of this disease, both before and after the diagnosis.

Conclusions: Diagnosis of acromegaly requires active medical involvement and awareness. Intervention of patientexperts in medical schools may help to be more aware of this disease. Endocrinologists caring for patients with acromegaly should also address the catastrophic dimension of the patient's experience and initiate the narrative to help them to put it into words for preventing harmful consequences such as social isolation and QoL impairment, but also anxiety or depression.
\end{abstract}

\section{Introduction}

Acromegaly is a rare disease characterized by excess secretion of growth hormone $(\mathrm{GH})$ and insulin-like growth factor 1 (IGF-I), most often attributed to a pituitary adenoma $(1,2)$. Its prevalence varies between 2.8 and 13.7 cases per 100000 persons, and its annual incidence between 0.2 and 1.1 cases per 100000 (3). It impairs patients' quality of life (QoL) (4) and is associated with
European Journal of

Endocrinology

(2019) 180, 339-352 cardiovascular, respiratory and metabolic complications that increase mortality (5).

Diagnostic delay is substantial, estimated at 4.5-5 years (3), and a recent study of 3173 patients reports a still longer median delay at diagnosis: 10 years for women and 8 for men (6). This diagnostic delay leads to psychosocial deterioration (7) and increases the 
risk of complications and of their persistence once the disease is controlled $(8,9)$. Early diagnosis of acromegaly is therefore a major issue in its management (10). The Endocrine Society's 2014 clinical practice guidelines point out the need for measuring IGF-1 in patients with typical clinical signs but also in those without these signs but with disorders associated with acromegaly, such as sleep apnea, type 2 diabetes, carpal tunnel syndrome, hyperhidrosis and chronic hypertension (11). Numerous approaches have been proposed to facilitate its diagnosis, including a screening score (12), software for analysis of facial photographs $(13,14)$ and data mining $(15,16)$.

Both the patient's place in treatment and the doctorpatient relationship have changed markedly in the past few years (17). Patients' expectations, their choices and their preferences now play a central role in care. New types of studies are being developed, focused on patients themselves, together with a new approach for assessing their health status: patient-reported outcomes (PROs). PROs are assessments reported directly by patients of their experiences, thoughts and perspectives concerning their disease and their medical care (18). Very few studies have explored the acromegaly patient's point of view on these diagnostic issues and only by quantitative - never qualitative - methods (19).

Qualitative methods focus on how individuals understand and report what they are experiencing: they are thus the methods of choice for exploring patients' perspectives (20). To the best of our knowledge, no qualitative study has yet examined the diagnostic pathway of subjects with acromegaly. The objective of this study was therefore to explore, through a qualitative approach, the diagnostic pathway of these patients in order to pinpoint the stakes of this diagnosis from their point of view and to identify ways to improve its recognition and management.

\section{Methods}

Our exploratory single-center study took place in the Service d'Endocrinologie et des Maladies de la Reproduction at Bicetre Hospital. The Paris-Descartes University Ethics Review Board (CERES) approved the study (IRB number: 20140600001072).

\section{Participants and recruitment}

Inclusion criteria for patients were male or female patients aged 18 or older, fluent in French, with a diagnosis of acromegaly based on clinical findings and elevated levels of serum insulin-like growth factor 1 (IGF-1) with unsuppressed levels of GH after oral glucose load and with a detailed history in the patient's file, particularly about the period between the first symptoms and the diagnosis of acromegaly. Treatment must have started at least 6 months before the interview. Exclusion criteria were psychiatric disorders or impairments of cognitive function that would prevent an informative interview.

The clinician coordinator (PC) identified potential participants who met the inclusion criteria and informed them about the study. If interested a preliminary meeting was organized, during which the researcher (EM) described the study and obtained the written consent from the patient. This preliminary interview also provided the occasion to collect social and demographic data as well as clinical information. Each participant also completed the Hospitalization Anxiety Depression (HAD) scale, a self-report questionnaire to assess anxiety and depression. Its aim was to ensure that the participants would not, because of the risks of depressive orders associated with acromegaly (21), recreate their anxious or depressive experience in their interviews. Consent has been obtained from each patient after full explanation of the purpose and nature of all procedures used.

At purpose, the recruitment followed a sampling strategy with maximal variation (22) for obtaining a heterogeneous sample except for the inclusion criteria, with a variety of cases different in terms of age, gender, medical history, duration of treatment and disease duration. Inclusion continued until saturation was reached (i.e., subsequent interviews provided no new elements), as recommended in qualitative research (20).

\section{Data collection}

Data were collected through face-to-face unstructured interviews, all conducted by one experienced qualitative researcher (EM) in French. The initiating prompt was 'Can you tell me about your disease since the first signs you perceived until today?' This approach suited our objective of obtaining an in-depth narrative. During the interview, the interviewer frequently prompted the participants to expand on their feelings and thoughts. All of them easily accepted open discussion. The interviews, which took place in a private room in the hospital in which the patients are followed, were audiotaped and transcribed verbatim. The interviews have been anonymized. At the end of the interview, if necessary, participants were referred for a visit with a psychiatrist or psychologist. 


\section{Data analysis}

We performed a thematic analysis $(23,24)$. First, we coded the material using descriptive codes. Then, conceptual notes were drafted, through processes of condensation, comparison and abstracting the initial notes. Connections between notes were then mapped and synthesized, and emergent themes were developed. Table 1 summarizes the different stages of our thematic analysis. The analyses were independently performed by three researchers (JS, EM, ARL) using N'vivo 11 software, and their subsequent triangulation ensured the rigor and intersubjectivity of the analytic process. Discrepancies were negotiated within the research team during regular meetings until agreement was reached. Reporting complies with COREQ statement (25).

\section{Results}

The study included 20 patients with acromegaly: 11 women and 9 men. Table 2 summarizes their characteristics. Their ages ranged from 33 to 71 years. The duration of misdiagnosis and uncertainty resulting in diagnostic delay ranged from 3 to 16 years (mean 8 years) and the period of care since diagnosis of acromegaly from 1 to 15 years. All had undergone surgery, except two patients (P3 who was interviewed before surgery and P10 who had only non-surgical treatment). Only four patients refused to participate: two gave no reason and two explained that it was too difficult for them to talk about this disease.

Our data analysis showed that the patients' experiences were structured around the moment of diagnosis. We have therefore chosen to present the results chronologically, describing what happened for patients (i) before and (ii) after the physician told them that the diagnosis of their disease was acromegaly. One theme emerged around (iii) the style or type of physician involved, which also follows a chronological line, and which we chose to present separately. Finally, we identified a fourth theme focused on (iv) patients' suggestions for limiting diagnostic delay. The results are presented below and relevant quotations (from the interview transcripts and translated from French into English for the purpose of this article) are given in Table 3.

\section{Before the diagnosis of acromegaly}

\section{Early symptoms perceived and reported by patients}

Misdiagnosis and uncertainty often resulted in a long diagnostic delay: 8 years on average. Some had perceived signs in childhood or adolescence, others only several months before diagnosis, even though the disease developed for two decades or more. Table 4 in supplemental data lists all of the initial signs reported by the patients. They described the development of these signs as 'insidious', 'very slow', or 'not at all sudden' (Q1).

\section{The terror of not recognizing oneself}

Many patients reported that before the diagnosis they had experienced a state of terror in response to their unexplained physical changes, being partially or totally unable to recognize themselves (Q2, Q3). They used words such as 'catastrophe' (Q4) and 'damage' (Q5) for speaking about this period and describing the physical

Table 1 Inductive thematic analysis.

$\overline{\text { Stage } 1} \frac{\text { Activities }}{\text { Repeatedly read each transcript as a whole }}$

Stage 2 Code the transcript by making notes corresponding to the fundamental units of meanings.

Stage 3 Make conceptual notes through processes of condensation, abstraction and comparison of the initial notes.

Stage 4 Identify initial themes.

Provide text quotes that illustrate the main ideas of each theme.

Stage 5 Identify recurrent themes across transcripts and produce a coherent ordered table of the themes and sub-themes.

\section{Rationale}

Obtain a global picture of the interview and become familiar with the interviewee's verbal style and vocabulary.

Each new reading of the transcript might also provide new perspectives.

Make descriptive notes using the participant's own words.

Categorize initial notes and reach a higher level of abstraction.

Themes are labels that summarize the essence of a number of related conceptual notes. They are used to capture the experience of the phenomenon under study.

Move from the particular to the shared across multiple experiences. Recurrent themes reflect a shared understanding of the phenomena among all participants.

During this more analytic stage, researchers try to make sense of the associations between the themes found. 
Table 2 Demographic characteristics of the 18 patients with acromegaly.

\begin{tabular}{|c|c|c|c|c|c|c|c|c|c|}
\hline Patients & Sex & $\begin{array}{l}\text { Marital } \\
\text { status }\end{array}$ & Age & $\begin{array}{c}\text { Age of } \\
\text { presumed } \\
\text { onset }\end{array}$ & $\begin{array}{c}\text { Age at } \\
\text { diagnosis }\end{array}$ & Comorbidities & Treatments received & $\begin{array}{c}\text { Duration of } \\
\text { treatment } \\
\text { (years) }\end{array}$ & $\begin{array}{l}\text { HAD score } \\
\text { (>8: presence } \\
\text { of symptoms) }\end{array}$ \\
\hline P1 & $\mathrm{M}$ & Married & 42 & - & 29 & HT, MNG, & $\begin{array}{l}\text { Surgery, gamma-knife, } \\
\text { pegvisomant }\end{array}$ & 13 & A: 16, D: 14 \\
\hline P2 & $\mathrm{F}$ & Married & 66 & 49 & 64 & HT, MNG, T2DM, CP & Surgery & NA & $A: 8, D: 3$ \\
\hline P3 & $\mathrm{M}$ & Married & 59 & 48 & 59 & MNG, CM, OSA & Surgery & NA & $A: 4, D: 1$ \\
\hline P4 & $\mathrm{F}$ & Single & 60 & 43 & 58 & $\begin{array}{l}\text { HT, MNG T2DM, } \\
\text { Arthritis }\end{array}$ & $\begin{array}{l}\text { Surgery, pegvisomant, } \\
\text { somatostatin analog }\end{array}$ & 2 & $A: 12, D: 3$ \\
\hline P5 & $\mathrm{F}$ & Married & 40 & 32 & 36 & - & Surgery & 4 & A: $12, \mathrm{D}: 4$ \\
\hline P6 & $\mathrm{M}$ & Married & 54 & - & 53 & MNG, OSA & $\begin{array}{l}\text { Surgery, somatostatin } \\
\text { analog }\end{array}$ & 1 & $A: 12, D: 1$ \\
\hline P7 & $\mathrm{F}$ & Married & 50 & 38 & 45 & MNG, OSA, CP & Surgery & 5 & $A: 5, D: 3$ \\
\hline P8 & $\mathrm{M}$ & Married & 51 & 45 & 50 & $\begin{array}{l}\text { MNG, CM, CP, } \\
\text { arthritis, PHP }\end{array}$ & Surgery & 1 & $A: 6, D: 2$ \\
\hline P9 & $\mathrm{F}$ & Married & 60 & 56 & 59 & Arthritis, osteoporosis & Surgery, cabergoline & 1 & $A: 4, D: 4$ \\
\hline P10 & $\mathrm{F}$ & Single & 46 & 37 & 44 & MNG, OSA, MNG & Somatostatin analog & 2 & $A: 5, D: 5$ \\
\hline P11 & $\mathrm{F}$ & Married & 33 & 20 & 30 & $\begin{array}{l}\text { Arthritis, } \\
\text { hypopituiarism }\end{array}$ & $\begin{array}{l}\text { Surgery, somatostatin } \\
\text { analog }\end{array}$ & 3 & A: 15, D: 16 \\
\hline P12 & $\mathrm{M}$ & Married & 36 & 16 & 21 & MNG, CM & Surgery, pegvisomant & 15 & A: 4, D: 2 \\
\hline P13 & $\mathrm{F}$ & Single & 70 & 62 & 70 & MNG, arthritis & Surgery & 1 & A:9, D: 2 \\
\hline P14 & $\mathrm{M}$ & Married & 35 & 30 & 34 & T2DM, OSA, obesity & $\begin{array}{l}\text { Surgery, somatostatin } \\
\text { analog }\end{array}$ & 1 & $X$ \\
\hline P15 & $\mathrm{M}$ & Single & 49 & 34 & 40 & - & $\begin{array}{l}\text { Surgery, somatostatin } \\
\text { analog }\end{array}$ & 9 & A: 10, D: 11 \\
\hline P16 & $\mathrm{F}$ & Married & 71 & 54 & 70 & $\begin{array}{l}\mathrm{HT} \text {, T2DM, MNG, } \\
\text { arthritis }\end{array}$ & $\begin{array}{l}\text { Surgery, somatostatin } \\
\text { analog }\end{array}$ & 1 & A: 3, D: 0 \\
\hline P17 & $\mathrm{F}$ & Married & 71 & 61 & 67 & $\begin{array}{l}\text { HT, T2DM, OSA, MNG, } \\
\text { arthritis }\end{array}$ & Surgery, pegvisomant & 4 & A: 14, D: 13 \\
\hline P18 & M & Married & 38 & 22 & 30 & OSA, MNG, CP & Surgery, pegvisomant & 8 & $A: 6, D: 2$ \\
\hline P19 & $\mathrm{M}$ & Married & 45 & 32 & 42 & HT, CM, CP arthritis, & $\begin{array}{l}\text { Surgery, somatostatin } \\
\text { analog }\end{array}$ & 3 & $A: 5, D: 0$ \\
\hline P20 & $\mathrm{F}$ & Married & 68 & $?$ & 63 & $\begin{array}{l}\text { HT, T2DM, CM, } \\
\text { OSA, MNG, }\end{array}$ & Surgery, pegvisomant & 5 & $X$ \\
\hline
\end{tabular}

CM, cardiomyopathy; CP, colon polyps; HAD, Hospitalization Anxiety Depression; HT, hypertension; MNG, multinodular goiter; OSA, obstructive sleep apneas; PHP, primary hyperparathyroidism; T2DM, type 2 diabetes mellitus.

transformations of their faces, hands and feet (Q6). Some, underlining the violence that their image caused them, explained that they no longer wanted to look at photographs of themselves or in the mirror (Q7).

\section{Lack of understanding}

Nearly all the patients in this study described a failure to understand the modifications they perceived in their bodies (Q8) and insisted on the difficulty of translating this experience in words (Q9). Some applied personal theories of causes, 'logical explanations' such as 'aging', 'weight gain', heredity, previous treatments, or their social, family or professional environments. Still others explained each symptom independently (Q10). Finally, some underlined the discrepancy between the real effects of the disease and the absence of a medical diagnosis or an explanation - for themselves and their families. They felt like 'hypochondriacs' (Q11).

\section{After the diagnosis}

When the patients received a correct diagnosis of acromegaly, its announcement was simultaneously able to explain experiences previously not understood, generate anxiety about becoming 'a monster' and induce a psychological breakdown.

\section{The announcement of the diagnosis: tragic ending}

The announcement of the diagnosis enabled most of patients to 'put words on their illness' but, at the same moment, signs the beginning of the disease period and 'lifelong treatment'.

Half of the patients considered the time of diagnostic announcement as a key moment of relief (Q12, Q13). At the same time, they experienced it ambivalently as both worrisome and reassuring (Q14). Most patients described a state of shock during this period that they compared 
Table 3 Representative patients quotations.

1. What happened before acromegaly was diagnosed

Early symptoms perceived Q1 I feel it's a very insidious disease. It takes place, little by little. So it's not a shock; you don't wake up and reported by patients

The terror of not recognizing oneself one morning saying, oh damn, my hands are bigger, my mouth has changed (P13).

Q2 I really didn't recognize myself, that's all ... I looked at myself, I thought I looked really strange (P16).

Q3 Yes, it was horrible. I didn't recognize myself anymore. At work, I didn't want anyone to take a picture of me. I just had the impression that I was someone else. I didn't take it at all well. (P7).

Q4 I suddenly felt that I had become very old, I had grown old, and in reality, I had. People who'd known me in the past could see that I was 20 kilos heavier and I looked it too. I had huge bags under my eyes. In the mornings, I woke up with my eyes super swollen and they stayed that way all day. I was swollen from the top down and sweating. For me, all this was a disaster (P7).

Q5 That does more damage, evidently (P2).

Q6 My feet were a catastrophe. I had calluses everywhere, and my feet hurt all over. I had foot cramps. I had to keep buying bigger and bigger shoe sizes, and my feet kept swelling (P8).

Q7 My features seemed deformed. I refused to accept it, but eventually the truth dawned. I took photos of the changes, but eventually, I couldn't look at myself in the mirror any more (P15).

Incomprehension Q8 What's happening to me (P11)?

Q9 It's very complicated to explain (P8).

Q10 You're going to find little contingent explanations. For each symptom (P15).

Q11 As best as I can remember, I said to myself, it hurts, I can't go away this weekend, I can't do things. I only felt ok in the dark, when nobody could see me. Those years were very unpleasant, difficult, as I didn't know what I had. I just felt the changes couldn't be possible, and that I must be a hypochondriac (P17).

2. What happened after the diagnosis was announced

At the diagnosis: Tragic ending

After the diagnosis: looking at the 'damage' in the 'rear-view mirror'
Q12 Eureka! I understood! (P3).

Q13 It's true that I was relieved when they gave it a name, when there was a word for it. That let me stop and relax a little (P9).

Q14 The diagnosis was worrisome, because you know that it might involve an operation, plus complicated treatments. But at the same time, you feel reassured, because there's a reason for all the changes after all (P9).

Q15 It feels like a death, let's say, an ending. The diagnosis is like BAM. It's like when you meet a doctor and you're told, ok, you have cancer. Well, when you leave the doctor's appointment after having been told the diagnosis, your life has changed from how it was when you first went in (P1).

Q16 It [the diagnosis] revealed 'that's not how you should be', there it is (P8).

Q17 It changes your perception of yourself and acceptance. So it may help to organize a follow-up at least, at least one or two consultations, propose psychotherapy (P15).

Q18 I'm ashamed of my hands and my feet. You can't do anything ... I have the impression that they're not feet, they're flippers (P7).

Q19 The changes hurt me too much; changed me physically too much. That's why I had this feeling of rejection. I didn't feel like this was an ordinary disease (P8).

Q20 In the pictures, it's horrible. When I see myself in a mirror, ok, but it's the photos. I look at them and say, it's not possible to be so ugly, it's just not possible. Yes, that hit me (P4).

Q21 I was hoping not to become a monster or I don't know what (P2).

Q22 You observe yourself because of the symptoms that affect your physical appearance, and of course, that raises questions. You look at yourself and say, what am I going to become? I think to myself, I don't want to become a monster. It may seem ridiculous, but I feel there's an association with the animated cartoon character, Shrek, the one without any colour (P8)

Q23 I have this image of myself as Shrek. It's as if I had become, not human, but a monster. I felt I wasn't me anymore (P7).

Q24 This all related to my face. I focused on it a little after the diagnosis. With some changes to my face, I knew it was associated with the disease. But after I learned I had this disease, I paid much more attention to how it had developed. So, after the diagnosis, I found that the changes got worse faster than before I was diagnosed (P18).

Q25 All at once, how I looked at myself changed... you see yourself in the rear-view mirror ... Signs that I reconstructed afterwards (P8).

Q26 The anxiety continues because the tumor could not be completely removed, because it was infiltrated in the bony tissue. So, the acromegaly is still active, but much weaker (P19).

Q27 It's very insidious as a disease, it's really not easy to detect (P15).

Q28 It's very insidious as a disease. Because you're sick, but you don't know it. You don't see it, or you don't want to see it (P19).

Q29 Because I don't know if in a month, or two months or three months, they're not going to find something else again. Which for the moment has not been diagnosed but which is going to be triggered ... (P3). 
Table 3 Continued.

Q30 Two words that still ring in my head when she told me the diagnosis, the words 'life expectancy'. Life span. Tumor, life span, all that (P19).

Q31 Now I feel afraid of everything. When you have acromegaly, you become anxious, and that's true. I've become anxious. For example, I can't travel anymore, because I'm afraid of planes. There are tons of things I planned to do when I retired but, now, well I just don't know (P17).

Q32 You think about it all the time (P1).

Q33 You always feel that things have become too much, which put me in these impossible states of stress. I would arrive home and feel demoralized. I feel I needed time to breathe, even just to take a week to take digest it (P10).

Q34 Because over the next six months I have at least 7 or 8 appointments, MRIs, blood tests, colonoscopies, Hospital, the neurosurgeon to see. Pff. It never really stops. It's not so much like that anymore, but well, it's to have a better follow-up, right? I tell myself it's for my own good, even if it's just for the moment, but it does bother me a little. All these appointments, sometimes I have them six months in advance. I make the list on my fridge so I don't forget, but sometimes I can see 6 or 7 appointments in a year. I'm going to have to buy a calendar! (P1).

Q35 Because it's true that when you're stopped because of looks, but after, if there's something else behind. When you talk or when after the girl says, yeah, you're different from the others or, inevitably (P1).

Q36 From the day I found out. I didn't go out anymore. Didn't go out, didn't have sex... I feel ugly (P8).

Q37 You get into the habit of being all alone. You make up a reason for it, but it just goes on and on. Eventually, you don't make plans anymore, you just do nothing. It lasts three months, then six months ... and it goes on. Then there are the disadvantage, that you can't get married, for example. Because knowing you can die at any moment, you're not really making life plans. When you're not married, it's better. If she wants, she can leave, and you don't owe anything to anyone (P1).

Q38 Well, my friends, finally, I, for example I'd have some, a weekend planned, and that I was in in those days where really, I felt awful... I cancelled everything, I didn't want to see anyone, I felt bad, but my friends understood. In any case, they saw that I had my nose all weird like that, my eyes here, they stopped insisting. I missed a lot of things (P17).

Q39 It dawned on my slowly that I was alone. That was just about bearable. But as soon as my son came to the house, just the fact that he talked to me was quite hard. It was like a migraine. When I was alone, I could just about cope. But when he arrives, I just couldn't stand it anymore (P5).

Q40 I feel that my emotional life is completely flat, zero. I find emotions difficult now. For now, they are finished (P4).

3. Types of doctors

Five types of doctors before the right diagnosis

At the diagnosis: Three types of doctors
Q41 When your doctor tells you, 'I don't know' you say well, I think it might be osteoarthritis, and things like that. Because, look at me, I have these nodules, what are they? But when I showed the doctor, she said she didn't know. Well, that's ok, when a doctor doesn't know. But then, really, if they don't know, they should then ask someone else (P2).

Q42 We did tests because since my father had gout, we said, ok, maybe it's that... at the end, it wasn't that. Then my doctor thought about multiple sclerosis, so we said, ok, we'll do an MRI, and then, all of a sudden, everything was better. So no more pain (P5).

Q43 Because the proof is, there were doctors who did see it. I think my GP, he missed it (P3).

Q44 General practitioners, when they know about acromegaly, it's good. But I think it's inevitable that when the doctor sees you regularly, they will miss the changes. Often it will be the locum doctor, seeing your for the first time, who notices something that the regular failed to spot (P8).

Q45 That might justify not being taken seriously because I was a hypochondriac ... for the doctor, it was psychosomatic (P5).

Q46 I kept complaining to the family doctor that I always had headaches, since I was about six or seven. In the end, they couldn't take out all the tumour, so now I am afraid for the future (cries). It's because of my general practitioner, he didn't listen to me, and the operation to remove the pituitary tumour was too late (P20).

Q47 My general practitioner, when I arrived with my story of my hair hurt, he made fun of me, but at no moment eh, I felt I was actually hearing what I was trying to say....(P5).

Q48 I saw a NET, telling him, I think I have a problem with my vocal cords. He looked at me, he said, 'You don't have anything regarding your vocal cords' and he looked at me and he scrutinized me carefully, he said to me, 'Madam, I know what you have, you must have acromegaly' ... he was especially someone who is very observant. Because it was like I was being observed, in detail, like I never had been before (P16).

Q49 The doctor, he looked at me, and he told me to show him my feet, and I showed them to him, and he said, show me your toes, I showed them, he said, it's acromegaly. He said to me, you see how big your feet are (P11).

(Continued) 
Table 3 Continued.

After the diagnosis: Two types of doctors

Q51 It was a flash of genius of Doctor R. ... But I think that yes, Doctor R had an intuition totally before it became major. The only thing I'm saying is the episode of R. because I found it brilliant, he's a real-life Doctor House, no but really ..., but here, I'm telling you because I find it pretty brilliant as an intuition (P15).Q52 I saw him turn white. But truly... He apologized for not having seen it ... On my head (P4).

Q53 My GP looked very vexed when he found out I had acromegaly. Yes, very agitated. When he saw the reports by Professor C, he seemed agitated. He said to me that he felt it wasn't possible that he didn't see I had acromegaly, but of course it's true. He told me it's a disease that's very little known about, but I knew, for sure I knew. So yes, he was disturbed by the findings. And after that, whenever I went to see him, he called me, 'my rare patient' (P17).

Q54 I ran into my GP again, after I had an operation for my acromegaly. So, it was not innocuous after all. It caused a moment of long silence by him (P5).

Q55 It's chains of top-flight doctors, people who are really great masters. And who know each other besides and respond to each other and trust each other, and at the same time, know what their skills are (P15).

Q56 I felt glad to meet Professor XX and he explained properly to me what I had, explained my symptoms and understood how I was feeling. I felt relief that I was finally with someone who understood how I'm feeling. So, he could confirm that this was more than something just in my head, this was something that I truly had. Yes, that was a relief (P7).

4. Participants' ideas of how to limit diagnostic delay

The medical gaze: better knowledge of acromegaly

Gazing at oneself, the gaze of others
Q57 Awareness by medical people (P16).

Q58 She said to me, no I don't know. When I told her the diagnosis she said to me, oh but this disease, I learned about it in medical school, but well, it's something I'm not really familiar with. I said, you've never had a patient who this disease? She said, No, or it hadn't been diagnosed .... That bothered me in the sense that, how can you be diagnosed if the healthcare professionals around you don't know the disease in question? It's rare but still ... I thought about it. That it's necessary, to inform people (P2).

Q59 On the other hand, clearly information for stomatologists [would be useful]; it would not be too much because I can't imagine I'm the only one to have seen that specialist for that and he was all the same ready to start a thing for surgery to shorten my jaw (P14).

Q60 It's a rare disease, compared with the rarity, doctors must already know the obvious physical signs, globally it's simpler and easier to retain for doctors who are not specialists compared with other rare diseases. I have the impression that the fact that it affects the physical appearance ... by looking at the person you can have clues, by looking at the person (P14).

Q61 That could be on a search engine, so a questionnaire on the computer where you could fill it out, yes I think that's it, afterwards, we all have obstacles. Me, my obstacle was talking about my appearance. And complaining to my doctor. I think in completing a questionnaire, I think that could be something, help for diagnosis because after that, you have to watch it (P7).

Q62 I didn't either, I was negligent, I didn't necessarily ask the doctor, push the examination further (P7).

Q63 I like to say it, anyway, I like to say it because it might concern the people I'm talking to, or raise some questions for them about their environment. Because I did lose some time (P8).

Q64: I should have said, ah, maybe I have this famous disease that I saw a story about on TV last night, maybe I have that. Certainly that. If I had seen one, but I've never heard or seen anything about this disease, you have the impression that it's the biggest secret in the world and that, it's true, it's pretty incredible, therefore when you have cancer or some other thing you know what it is, you can talk about it... but l'd never seen anything, if I'd seen a story or a program saying ... well, we're going to show you patients who have this disease called acromegaly. Jaw deformation, I would have watched that, I would have said, oh, wow, that's exactly what I have, deformation of the hand, there I would have called a doctor, because I would have been alerted, but who alerted me? No one since no one said anything. Just behind my back, criticizing me, saying l'd had botched plastic surgery. Yes that's really important (P13).

Q65: Maybe there should be information campaigns. Because information campaigns about, for example, cardiac diagnosis, that's very useful, well, I should say that there are lots more heart attacks than acromegaly. So there's also a problem of investment, of economic profitability, but now everyone knows that if you have pain here or if you have pain, pay attention, you need to see a doctor fast. I think that a prevention campaign, maybe first, for doctors, because doctors, I've seen them ... like everyone has (P16). 
to the diagnostic announcement of malignancy (Q15). The diagnosis made them aware of a physical anomaly and revealed to them a body image different from what it should have been (Q16). The potential help of a psychological support was suggested (Q17).

Afterwards many patients reported a feeling of shame or of rejection of their bodies (Q18, Q19), in terms within the lexical field of ugliness (Q20). Some even mentioned the fear of becoming a monster and the need to scrutinize the smallest physical changes (Q21, Q22). The monstrous, inhuman dimension was underlined in a comparison with the movie character Shrek (Q23).

\section{After the diagnosis: looking at the 'damage' in the 'rear- view mirror'}

After the diagnosis, many patients became obsessed with being looked at - by themselves or others: the themes of verification and scrutiny were coupled with an experience of strangeness, of being disoriented looking at their own image (Q24). Many of the terms used, such as 'suddenly', 'the day when', 'before, now', 'retrospectively', 'after the fact', 'a posteriori', expressed the sudden change in their self-gaze (how they looked at themselves) (Q25).

Many patients expressed a sensation of invasion by the disease at every level of their lives (physical, psychological, daily routine, etc). The idea of an invasive 'infiltrating' disease and the fear of its progression to the internal organs appeared in the interviews, along with the impression of living under a constant threat of danger (Q26). The adjective 'insidious' applied to the disease suggests the idea of something malevolent dissimulated in their bodies, something disseminating without their knowledge (Q27, Q28). They worried about their future due to the insidious progression of the disease (Q29), its effect on their physical appearance and their reduced life expectancy $(\mathrm{Q} 30)$. In this context, some described the onset of symptoms of anxiety (Q31).

Many patients reported that the disease invaded their minds, that they thought obsessively about it (Q32). The aspects of weariness and low morale demonstrated in the interviews were also signs of a potential depressive experience (Q33). The examinations, multiple medical visits, work-ups and treatments encroached on their daily lives and were described as a constraint and the principal change in their lives (Q34).

The announcement of the diagnosis sometimes also induced some relationship breakdowns, with direct consequences on intimacy and sexual relationships (Q35), the patient's appearance being now an obstacle for meeting people with whom it could be possible to have sexual relationships (Q36). Some described increasingly fragile emotional bonds, a difficulty in committing into a lasting relationship or the impossibility of envisioning one (Q37). But this effect on relationships preceded the diagnosis: some of the patients described a feeling of a wasted or ruined life (Q38), while others, especially mothers, stressed the effect on family life (Q39) or their lack of an emotional life (Q40).

\section{The types of physicians}

The healthcare path for patients with acromegaly was studded with meetings with different types of doctors encountered along the often long and winding road to this diagnosis, as well as afterward.

\section{Five types of physicians before the right diagnosis}

During the phase preceding the diagnosis, most of the physicians they consulted did not recognize acromegaly — ignorance that led to a long diagnostic delay averaging 8 years. Patients described five types of physicians: the ones who said, 'I don't know', those who looked for and did not find, those who did not see, those who did not believe and those who did not listen.

Those who said, 'I don't know': some physicians stated their ignorance about the symptoms presented by the patient (Q41).

Those who looked for and did not find: some physicians searched in vain for the cause of the symptoms reported without reaching the diagnosis of acromegaly (Q42).

Those who did not see: the verb 'to see' in the negative form (Q43) refers to the idea of a diagnosis made at inspection that the physicians met during the period of misdiagnosis or uncertainty were not able to do. One patient suggested that family doctors might be too close to see the physical changes $(\mathrm{Q} 44)$.

Those who did not believe: some physicians raised questions about the patients' discourse or considered them responsible for what they were complaining about (Q45).

Those who did not listen: the doctors who by not listening to what the patients were complaining about made them feeling like 'beggars' (Q46, Q47).

\section{At diagnosis: three types of doctors}

Patients reported three types of doctors at diagnosis: those who saw, found and diagnosed by looking; those who 
Table 4 The first signs perceived and reported.

Pain
Reproduction/sexual
relations

Deformities of the body
Headaches or migraines

'I always had these headaches that got stronger and stronger, then I had this impression of having needles pushed, also in my temples. It felt like knitting needles being pushed inside my head' (P5)

Pain in the joints and carpal tunnel

'I felt huge pain in my pelvis and leg joints. That lasted for about two to three months. If I was sitting, I just couldn't stand up, and when I eventually did get up, it took me ten minutes before I could start to walk' (P5)

\section{Libido problems}

'With all the problems with hormones, of growth hormones for example, you don't have the same feelings as others. For example, with girls, I don't have the same expectations. I can go for a month or three months without going to bed with a girl, and then, I don't have the same desires that I had before' (P1).

\section{Infertility}

'When I became an adult, I started to have problems with my periods. I had my first period at 14, but about three years later, it stopped, and I didn't have any more periods. I went to see a doctor, but he couldn't find any problem. So, I stayed like that, and now I can't get pregnant' (P11).

\section{Changes of hands and feet}

'The first signs are deformities, of the feet and hands. My shoe size changed, and my hands got so big that I couldn't wear my jewelry anymore. What affects me most are the hands, they're not pretty ones, and when they got bigger, I started to try and hide my hands. Or I wear long sleeves, and just wondered if the deformities would continue' (P9).

Become thicker, enlarged, feel swollen

'I felt swollen, in any case, I had the sensation of being swollen, blown up. Because it wasn't even fat, it was more muscles. Yes, it was like the muscle developed, it wasn't fat. My husband told me, you're muscular' (P7).

\section{Growth}

'I grew too, between 16 and 18 years, I grew 20 to $30 \mathrm{~cm}$ all at once' (P12).

Skull deformity

'My skull was deformed' (P7).

Face

Facial deformity

Associated with premature aging: 'deep wrinkles' (P7); 'deformity of features' (P15); 'Me, I took it as aging. With features that became furrows, wrinkles. I said to myself: eh, I'm over 50 years, that's normal' (P3).

Associated with a change in the appearance of the mouth: 'The lips, yes I saw that my lips had, they had thickened, ok, now they've gone back, more or less, to their normal size ... No, I, it's especially at, yes, around the mouth' (P16.)

Jaw coming forward and smile deformed

'My head isn't the same, I had a round head, now it's oval, my jaw's moved forwards, I've lost teeth too, teeth fell out, lots of things go with it, little by little, you realize that, the more the years pass...' (P12).

'The lower jaw, which actually moved apart, my four incisors moved behind, the upper incisors went behind the lower ones; it wasn't like that before. And that meant, I tell you, a really long time that I had jaw pain, and they kept saying, no, there's nothing, your teeth are healthy, eh... I asked myself anyway, I said so and I didn't think so, still. This disease, eh, finally it had plenty of physical signs' (P2).

'When I smiled, I had 50000 teeth, you only saw that, so I had a pretty nice smile, in any case, lovely white teeth. And a while ago, I found that it's strange, when I smile, since my lips have gotten thicker, you can't see my teeth anymore, so I realized that...' (P13).

\section{Thickening of the face}

'a fat face' (P19)

(About the face) 'puffed up' (P9)

(About the face) 'swollen' (P11)

Changing bite and spaces, tooth problems

'My front teeth are moving apart and they don't understand because, by the way, my teeth are very solid, but the jaw is moving apart, and I wasn't managing to make the link with all that' (P10).

\section{Lower face that changed}

'It's clear that the bottom of the face, it's not the same' (P10).

Other

\section{Major fatigue}

'When I woke up in the morning, I was tired. I was always tired' (P7).

Progressive weight gain

'I started to gain around 2 kilos every year. Two or three kilos'(P7).

Hypertension

'I had high cholesterol, I gained weight, but I dieted and nothing worked, I had high blood pressure, and I have a very fragile heart' (P17).

Excessive perspiration

'Nocturnal and diurnal sweating. Unexplained' (P3). 
became involved and asked good questions; and those who had a 'flash of genius'.

Those who saw, found and diagnosed by looking: with the entire lexical field of looking, gazing: see, look at, stare at, observe, observant, show and face (Q48, Q49).

Those who became involved, who asked good questions: 'attentive doctors', 'vigilant', 'receptive', 'involved', and 'curious' (Q50).

Those who had a 'flash of genius': the description of the 'fantastic, brilliant' dimension of the doctor who found the disease appeared to suggest that the result was the outcome of the doctor's talent and singularity rather than the application of intelligence to the corpus of medical science (Q51). The idea of being diagnosed was then considered 'luck' (P5). Oral surgeons were often mentioned as an example because of the dental problems associated with acromegaly.

These results showed the singularity of the very nature of the diagnosis made by the medical gaze (by looking at the patient) and of the doctors who found it.

\section{After the diagnosis: two types of doctors}

After the diagnosis was reached, general practitioners were described as vexed, or feeling guilty or indifferent. On the other hand, the specialists were seen as saviors, seasoned and those who provide care.

Those who turn white, become vexed or feel guilty: The reactions of the doctors who were embarrassed or felt guilty (Q52) could have been expected; those of the doctors who were vexed was surprising (Q53) and those of the doctors who showed indifference disturbing (Q54).

The type of the expert specialist: the majority of patients meeting a specialist along their healthcare path found that this encounter was a key moment for them. They felt cared for by a trained team in a specialized center; this reinforced their confidence (Q55). They also felt that their previously mysterious experience was now understood (Q56).

\section{Participants' ideas of how to limit diagnostic delay}

Some patients offered two avenues for improving the promptness of diagnosis: one directly concerns doctor training and the other involves how society, patients and others look at people with acromegaly, as well as the need to look more attentively at oneself and at others.

\section{The medical gaze: better knowledge of acromegaly}

This idea to improve the diagnosis involves better knowledge of acromegaly by doctors (Q57). Many patients underlined the lack of knowledge of the doctors they had seen (Q58). Some considered that dentists and stomatologists in particular required training (Q59). Others thought that the visibility of the disease ought to facilitate the diagnostic procedure (Q60).

Finally, to overcome the difficulty of patients and doctors jointly approaching this issue of appearance, one woman even proposed a computerized questionnaire as a diagnostic tool (Q61).

\section{A gaze on oneself, the gaze of others}

Most patients wondered about the role of society and of the nonmedical gaze to improve early diagnosis. They consider that it is by looking - by looking at oneself and being looked at by others - that the diagnostic procedure might begin. Similarly, they emphasized the patients' responsibility as a condition at diagnosis: they need to be proactive for their health and dare to ask doctors questions (Q62). Some wanted to testify about their experience and share their 'sharpened eyes' (P15) to help others ask themselves questions and detect potential acromegaly earlier - in themselves or among their families or friends (Q63).

Moreover, some patients suggested the idea of raising public awareness of this disease, through various media, such as television or radio programs or news stories, and even 'news flashes', information campaigns or slogans (Q64, Q65).

\section{Discussion}

This is the first qualitative study exploring the subjective experience of diagnostic delay in patients with acromegaly.

Our results allow us to examine two original points: (i) the direct associations between diagnostic delay and the doctor-patient encounter and (ii) the truly catastrophic experience of this disease, both before and after the diagnosis.

\section{Diagnostic delay and the issues in doctor- patient encounters}

Recent studies have shown a relative reduction in the diagnostic delay (3-6 years), attributed to either factors related to the improvement in the use and quality of biochemical measurements such as GH and IGF-I (26) or better awareness of the disease among endocrinologists but also patients who have now easy access to more information, thanks to the Internet (19). 
What seems to remain an issue for reducing the delay, as suggested by our results, is the patient-doctor encounter. Indeed, acromegaly has an insidious onset, with clinical features that overlap those of other common disorders (27). Patients most likely would consult different medical specialists for each clinical manifestation (28). Several authors have already underlined the major role of primary care doctors in the diagnosis of acromegaly (29). The literature emphasizes the key role of any doctor, whatever his specialty, to identify the signs, symptoms and comorbidities of acromegaly (10). The first health care providers to be visited by these patients, such as dental professionals for instance, need to get involved and 'see the unseen' in order to identify as early as possible the disease (30). Our results suggest that seeing the unseen is not enough if physicians do not say the unsaid.

Retrospectively, all the patients of our study reported that they had identified typical but often isolated signs of acromegaly long before diagnosis. Many patients did not allow themselves to mention them during visits to the doctor. A recent study has shown discrepancies between the reporting of clinical manifestations of acromegaly by the patient and by the physician, especially functional symptoms such as snoring syndrome, weight gain and enlarged hands or feet (16). This raises the issues of symptoms being dismissed by physicians and of the reluctance of patients to speak about these symptoms during visits. Here, our results underline these issues of communication between doctors and patients, especially around what patients feel that it is justified or allowed to say during a consultation. The literature describes several factors that keep patients, especially those with chronic diseases, from speaking openly to their doctors: shame, social discomfort, guilt and self-blame (31). Other studies have also underlined patients' difficulties in recognizing some signs as health related and in determining what is relevant to share with the doctor (32). Here, the patients might have related these typical signs to esthetic discomfort or embarrassment without perceiving them as medical issues. Holistic approaches such as patientcentered communication (33) and narrative medicine (34) might be favored by primary care doctors to overcome these obstacles to communication, to disclose symptoms the patients might have not shared and to uncover unusual symptom combinations that might lead to suspect an acromegaly.

Other patients did talk explicitly to their doctors about these signs, often to several physicians over the same period, but still without inducing the doctors to suspect acromegaly, despite sometimes extensive medical explorations. The patients appear, we think, to have adapted to the system of specialized medicine and raised each clinical sign with the corresponding specialist. In these patients' histories, no doctor appeared to have had a comprehensive clinical view before the diagnosis. It appears that the doctors who successfully diagnosed the patient allowed themselves to question the patient proactively and to consider clinical processes beyond their own specialty, because they suspected acromegaly from a symptom mentioned or a sign observed.

All these issues of patient-doctor meeting point toward deficiencies in the medical world's awareness of acromegaly and in doctors' clinical training. Acromegaly is a rare disease that doctors see very rarely and are therefore unlikely to think about. Several authors have already pointed out that early diagnoses could occur more often if doctors were more aware of acromegaly and thus more likely to consider it as a diagnosis (9). In this context, we propose the intervention of patient-experts (35) in medical schools, to make students aware of acromegaly and its diagnostic problems. These patient-experts could recount the diagnostic errors that led to diagnostic delay, describe their early and current clinical signs and make future doctors aware of the need for a high level of suspicion and active questioning to reach a diagnosis. The students would thus have access to a narrative combining the experience of diagnostic errors and the importance of the doctor-patient communication for this diagnosis. A doctor who has received this training may be more likely to think of the signs observed or reported as potential indicators of acromegaly. This approach, focused on the clinical encounter and doctor-patient communication, differs from but is complementary to various innovations proposed to reduce diagnostic delay for acromegaly (13, $14,15,16)$. It could also include the use of a screening score such as the Acroscore (12) to facilitate doctor-patient interaction and the doctor's active approach. However, we must acknowledge that such process for improving knowledge could be considered, not only for acromegaly but also for any rare disease. Implementing this approach for (too) many rare diseases would be a real challenge for medical schools.

\section{A catastrophic experience}

Literature concerning QoL and psychiatry comorbidities among patients with acromegaly is abundant. Poor and decreased QoL has been described among these patients, both before and after treatment $(36,37)$. A qualitative study about QoL performed in patients with pituitary 
diseases (38) reported specific features such as issues with a desire to have children, sadness, frustration and a reduced social network, which were also observed in our study

The strongest predictors for QoL among patients with acromegaly appear to be diagnostic delay, appearance and psychiatric comorbidities (39). In fact, all these aspects appear to be related with each other. Diagnostic delay is directly correlated with psychosocial distress and decreased quality of life (7) and the presence of an anxiety disorder or depressive disorder associated with acromegaly is directly responsible for QoL impairment $(40,41)$. Appearance, especially of the face, is considered the most affected dimension and has the highest impact on QoL (39), even after long-term remission (42). Physical changes associated with acromegaly are directly correlated with poor psychological outcomes (43) and depression contributes to negative body image among these patients (44). There is also considerable psychiatric comorbidity among patients with acromegaly (45), mainly anxiety and depression. Obesity and depression are consistent factors associated with poor QoL among patients with acromegaly and should be the targets of specific interventions $(40,41)$.

Nonetheless, out of the 20 patients of our study, only four showed simultaneous anxiety and depression symptoms on their HADS score and four more symptoms of anxiety alone. This experience of anxiety and depression probably colored the specific experience of acromegaly for these eight patients, but our results also give us access to another aspect of their distress. All the aspects described in the literature - appearance, psychological outcomes, QoL impairment - were also found in our study, but rather than considering them separately, patients had a holistic view and described a global, catastrophic experience. In fact, all the patients told about a catastrophe, some of them explicitly using that term. This catastrophic experience affected multiple aspects of their lives - physical health and appearance, identity and relationships. At the same time it is difficult for them to put into words. Only the dialog established during these in-depth interviews enabled them to unpack their experience through a narrative that enabled the emergence of what had not been identifiable until then.

Gurel et al. (28) also reported patients' hesitation and difficulty in raising and sharing with their healthcare professionals the impact of the disease on their lives and suggested, quite pertinently, that setting up support and discussion groups for patients with acromegaly could be useful; they also insisted on finding ways to reach a better collaboration between patients and professionals. Indeed, patients find it difficult to communicate about their disease (38). Further research is needed to explore in-depth this catastrophic experience and the difficulty for patients to put into words their live experience both before and after the diagnosis. This could lead to specific interventions that would reduce the burden of the disease, QoL impairments and psychological distress.

Diagnosis requires active medical involvement in eliciting the necessary facts and potential diagnoses; and a person-centered holistic approach, that is to consider the person as a whole and take into consideration his or her overall catastrophic experience and not to focus only on specific aspects separately. Such approach would empower the physician in his or her ability to diagnose acromegaly.

Similarly, we consider that physicians and especially endocrinologists caring for patients with acromegaly must be active and initiate the narrative to help their patients to put this catastrophic experience into words. This will help to prevent harmful consequences such as social isolation and QoL impairment, but also psychiatric complications such as anxiety or depression. It should also enable better engagement in treatment, by strengthening the therapeutic alliance and enabling better quality of care, focused on the patient, for example, to better target potential surgical repair.

\section{Limitations}

This is the first qualitative study looking at the experience of the diagnostic path of patients with acromegaly.

Nonetheless, some limitations must be taken into consideration. First, it took place in France and caution is required in transposing our results to other places because medical care depends strongly on the organization of the medical system as well as on the country's economy. Second, this was a single-center study; it would be interesting to see the results of other studies reproducing this design in other medical settings. Third, some might question the specificity of the experience of disastrous damage to the patients' identities reported here. Future qualitative studies could be conducted on this subject among other populations of patients who have experienced substantial physical deformities, from surgical treatment of patients with NET cancer patients or with face graft. Similarly, some might also question whether our results are only specific to acromegaly or to any rare disease with diagnostic delay. To our knowledge, no similar qualitative studies have ever explored such issue among other rare diseases. We found only one mixed-methods study on this matter regarding light-chain amyloidosis (46). Results 
also mentioned the emotional impact and the influence of patient's perceptions of their initial symptoms and authors also concluded on the importance of increasing clinician awareness for a better early identification. Further studies should compare the experiences of diagnostic delay in several rare diseases in order to better understand their similarities and differences.

Finally, given the specific context of this study and its qualitative methodology, we would not claim that it is generalizable; instead, we think that it meets the aim of qualitative research: it may be transferable to other contexts.

\section{Declaration of interest}

A R-L and J $S$ have received a research grant from Ipsen, paid to their institution. P C has received unrestricted research and educational grants from Ipsen, Novartis and Pfizer as head of the Department of Endocrinology and Reproductive Diseases, Hôpitaux Universitaires ParisSud; he has served as investigator for clinical trials funded by Antisense, Chiasma, Ipsen, Italpharmaco, Novartis and Pfizer and is a consultant for Ipsen, Novartis and Pfizer. All fees and honoraria are paid to his institution.

\section{Funding}

This research did not receive any specific grant from any funding agency in the public, commercial or not-for-profit sector.

\section{Acknowledgments}

The authors thank Fatine Elaraki for her help during the conception of this study, Jo Ann Cahn for the translation of the manuscript and Jon Danzig for the preparation of the manuscript.

\section{References}

1 Chanson P, Salenave S \& Kamenicky P. Acromegaly. Handbook of Clinical Neurology 2014124 197-219. (https://doi.org/10.1016/B9780-444-59602-4.00014-9)

2 Melmed S. Acromegaly pathogenesis and treatment. Journal of Clinical Investigation 2009119 3189-3202. (https://doi.org/10.1172/ JCI39375)

3 Lavrentaki A, Paluzzi A, Wass JA \& Karavitaki N. Epidemiology of acromegaly: review of population studies. Pituitary 201720 4-9. (https://doi.org/10.1007/s11102-016-0754-x)

4 Ben-Shlomo A, Sheppard MC, Stephens JM, Pulgar S \& Melmed S. Clinical, quality of life, and economic value of acromegaly disease control. Pituitary 201114 284-294. (https://doi.org/10.1007/s11102011-0310-7)

5 Colao A, Ferone D, Marzullo P \& Lombardi G. Systemic complications of acromegaly: epidemiology, pathogenesis, and management. Endocrine Reviews 200425 102-152. (https://doi. org/10.1210/er.2002-0022)

6 Petrossians P, Daly AF, Natchev E, Maione L, Blijdorp K, SahnounFathallah M, Auriemma R, Diallo AM, Hulting AL, Ferone D et al. Acromegaly at diagnosis in 3173 patients from the Liege Acromegaly Survey (LAS) database. Endocrine-Related Cancer 201724 505-518. (https://doi.org/10.1530/ERC-17-0253)

7 Siegel S, Streetz-van der Werf C, Schott JS, Nolte K, Karges W \& Kreitschmann-Andermahr I. Diagnostic delay is associated with psychosocial impairment in acromegaly. Pituitary 201316 507-514. (https://doi.org/10.1007/s11102-012-0447-z)

8 Abreu A, Tovar AP, Castellanos R, Valenzuela A, Giraldo CM, Pinedo AC, Guerrero DP, Barrera CA, Franco HI, Ribeiro-Oliveira A Jr et al. Challenges in the diagnosis and management of acromegaly: a focus on comorbidities. Pituitary 201619 448-457. (https://doi. org/10.1007/s11102-016-0725-2)

9 Reid TJ, Post KD, Bruce JN, Nabi Kanibir M, Reyes-Vidal CM \& Freda PU. Features at diagnosis of 324 patients with acromegaly did not change from 1981 to 2006: acromegaly remains underrecognized and under-diagnosed. Clinical Endocrinology 201072 203-208. (https://doi.org/10.1111/j.1365-2265.2009.03626.x)

10 Brue T \& Castinetti F. The risks of overlooking the diagnosis of secreting pituitary adenomas. Orphanet Journal of Rare Diseases 2016 11 135. (https://doi.org/10.1186/s13023-016-0516-x)

11 Katznelson L, Laws ER, Jr, Melmed S, Molitch ME, Murad MH, Utz A, Wass JA \& Endocrine Society. Acromegaly: an endocrine society clinical practice guideline. Journal of Clinical Endocrinology and Metabolism 201499 3933-3951. (https://doi.org/10.1210/jc.20142700)

12 Prencipe N, Floriani I, Guaraldi F, Di Giacomo SV, Cannavo S, Arnaldi G, Berton A, Torri V, Spinello M, Arvat E et al. ACROSCORE: a new and simple tool for the diagnosis of acromegaly, a rare and underdiagnosed disease. Clinical Endocrinology 201684 380-385. (https://doi.org/10.1111/cen.12959)

13 Kong X, Gong S, Su L, Howard N \& Kong Y. Automatic detection of acromegaly From facial photographs using machine learning methods. EBioMedicine 201827 94-102. (https://doi.org/10.1016/j. ebiom.2017.12.015)

14 Miller RE, Learned-Miller EG, Trainer P, Paisley A \& Blanz V. Early diagnosis of acromegaly: computers vs clinicians. Clinical Endocrinology 201175 226-231. (https://doi.org/10.1111/j.13652265.2011.04020.x)

15 Broder MS, Neary MP, Chang E, Cherepanov D \& Katznelson L. Treatments, complications, and healthcare utilization associated with acromegaly: a study in two large United States databases. Pituitary 201417 333-341. (https://doi.org/10.1007/s11102-013-0506-0)

16 Caron P, Brue T, Raverot G, Tabarin A, Cailleux A, Delemer B, Renoult PP, Houchard A, Elaraki F \& Chanson P. Signs and symptoms of acromegaly at diagnosis: the physician's and the patient's perspectives in the ACRO-POLIS study. Endocrine 201963 120-129. (https://doi.org/10.1007/s12020-018-1764-4)

17 Truog RD. Patients and doctors - evolution of a relationship. New England Journal of Medicine 2012366 581-585. (https://doi. org/10.1056/NEJMp1110848)

18 Deshpande PR, Rajan S, Sudeepthi BL \& Abdul Nazir CP. Patientreported outcomes: a new era in clinical research. Perspectives in Clinical Research 20112 137-144. (https://doi.org/10.4103/22293485.86879)

19 Kreitschmann-Andermahr I, Siegel S, Kleist B, Kohlmann J, Starz D, Buslei R, Koltowska-Haggstrom M, Strasburger CJ \& Buchfelder M. Diagnosis and management of acromegaly: the patient's perspective. Pituitary 201619 268-276. (https://doi.org/10.1007/s11102-0150702-1)

20 Mays N \& Pope C. Qualitative research in health care. Assessing quality in qualitative research. BMJ 2000320 50-52. (https://doi. org/10.1136/bmj.320.7226.50)

21 Szczesniak D, Jawiarczyk-Przybylowska A \& Rymaszewska J. The quality of life and psychological, social and cognitive functioning of patients with acromegaly. Advances in Clinical and Experimental Medicine 201524 167-172. (https://doi.org/10.17219/acem/38156)

22 Orri M, Sibeoni J, Bousquet G, Labey M, Gueguen J, Laporte C, Winterman S, Picard C, Nascimbeni C, Verneuil L et al. Crossing the perspectives of patients, families, and physicians on cancer treatment: a qualitative study. Oncotarget 20178 22113-22122. (https://doi.org/10.18632/oncotarget.12770) 
23 Braun V, Clarke V \& Terry G. Thematic analysis. In Qualitative Research in Clinical and Health Psychology. Eds P Rohleder \& A Lyons. Basingstoke, UK: Palgrave Macmillan, 2014.

24 Braun V \& Clarke V. What can 'thematic analysis' offer health and wellbeing researchers? International Journal of Qualitative Studies on Health and Well-Being 20149 26152. (https://doi.org/10.3402/qhw. v9.26152)

25 Tong A, Sainsbury P \& Craig J. Consolidated criteria for reporting qualitative research (COREQ): a 32-item checklist for interviews and focus groups. International Journal for Quality in Health Care 200719 349-357. (https://doi.org/10.1093/intqhc/mzm042)

26 Clemmons DR. Consensus statement on the standardization and evaluation of growth hormone and insulin-like growth factor assays. Clinical Chemistry 201157 555-559. (https://doi.org/10.1373/ clinchem.2010.150631)

27 Vilar L, Vilar CF, Lyra R, Lyra R \& Naves LA. Acromegaly: clinical features at diagnosis. Pituitary 201720 22-32. (https://doi. org/10.1007/s11102-016-0772-8)

28 Gurel MH, Bruening PR, Rhodes C \& Lomax KG. Patient perspectives on the impact of acromegaly: results from individual and group interviews. Patient Prefer Adherence 20148 53-62. (https://doi. org/10.2147/PPA.S56740)

29 Nachtigall L, Delgado A, Swearingen B, Lee H, Zerikly R \& Klibanski A. Changing patterns in diagnosis and therapy of acromegaly over two decades. Journal of Clinical Endocrinology and Metabolism 200893 2035-2041. (https://doi.org/10.1210/jc.20072149)

30 Agrawal M, Maitin N, Rastogi K \& Bhushan R. Seeing the unseen: diagnosing acromegaly in a dental setup. Case Reports 20132013 bcr2013200266. (https://doi.org/10.1136/bcr-2013-200266)

31 Duncan C \& Cacciatore J. A systematic review of the peer-reviewed literature on self-blame, guilt, and shame. Omega 201571 312-342. (https://doi.org/10.1177/0030222815572604)

32 Lim C, Berry ABL, Hirsch T, Hartzler AL, Wagner EH, Ludman E \& Ralston JD. 'It just seems outside my health': how patients with chronic conditions perceive communication boundaries with providers. DIS (Conference on Designing Interactive Systems) 20162016 1172-1184.

33 Alpert JM, Dyer KE \& Lafata JE. Patient-centered communication in digital medical encounters. Patient Education and Counseling 2017100 1852-1858. (https://doi.org/10.1016/j.pec.2017.04.019)

34 Zaharias G. Learning narrative-based medicine skills: narrative-based medicine 3. Canadian Family Physician Medecin de Famille Canadien $201864352-356$.

35 Elberse JE, Caron-Flinterman JF \& Broerse JE. Patient-expert partnerships in research: how to stimulate inclusion of patient perspectives. Health Expectations 201114 225-239. (https://doi. org/10.1111/j.1369-7625.2010.00647.x)
36 Crespo I, Valassi E \& Webb SM. Update on quality of life in patients with acromegaly. Pituitary 201720 185-188. (https://doi. org/10.1007/s11102-016-0761-y)

37 Solomon E, Branisteanu D, Dumbrava A, Solomon RG, Kiss L, Glod M \& Preda C. Executive functioning and quality of life in acromegaly. Psychology Research and Behavior Management 201912 39-44. (https://doi.org/10.2147/PRBM.S183950)

38 Andela CD, Niemeijer ND, Scharloo M, Tiemensma J, Kanagasabapathy S, Pereira AM, Kamminga NG, Kaptein AA \& Biermasz NR. Towards a better quality of life (QoL) for patients with pituitary diseases: results from a focus group study exploring QoL. Pituitary 201518 86-100. (https://doi.org/10.1007/s11102-014-0561-1)

39 Webb SM \& Badia X. Quality of life in acromegaly. Neuroendocrinology 2016103 106-111. (https://doi.org/10.1159/000375451)

40 Geraedts VJ, Andela CD, Stalla GK, Pereira AM, van Furth WR, Sievers C \& Biermasz NR. Predictors of quality of life in acromegaly: no consensus on biochemical parameters. Frontiers in Endocrinology 20178 40. (https://doi.org/10.3389/fendo.2017.00040)

41 Geraedts VJ, Dimopoulou C, Auer M, Schopohl J, Stalla GK \& Sievers C. Health outcomes in acromegaly: depression and anxiety are promising targets for improving reduced quality of life. Frontiers in Endocrinology 20145 229. (https://doi.org/10.3389/ fendo.2014.00229)

42 Roerink SH, Wagenmakers MA, Wessels JF, Sterenborg RB, Smit JW, Hermus AR \& Netea-Maier RT. Persistent self-consciousness about facial appearance, measured with the Derriford appearance scale 59, in patients after long-term biochemical remission of acromegaly. Pituitary 201518 366-375. (https://doi.org/10.1007/s11102-014-0583-8)

43 Imran SA, Tiemensma J, Kaiser SM, Vallis M, Doucette S, Abidi E, Yip CE, De Tugwell B, Siddiqi F \& Clarke DB. Morphometric changes correlate with poor psychological outcomes in patients with acromegaly. European Journal of Endocrinology 2016174 41-50. (https://doi.org/10.1530/EJE-15-0888)

44 Dimopoulou C, Leistner SM, Ising M, Schneider HJ, Schopohl J, Rutz S, Kosilek R, Frohner R, Stalla GK \& Sievers C. Body image perception in acromegaly is not associated with objective acromegalic changes but depends on depressive symptoms. Neuroendocrinology 2017105 115-122. (https://doi. org/10.1159/000448519)

45 Szczesniak DM, Jawiarczyk-Przybylowska A, Matusiak Ł, Bolanowska A, Maciaszek J, Sieminska M, Rymaszewska J \& Bolanowski $\mathrm{M}$. Is there any difference in acromegaly and other chronic disease in quality of life and psychiatric morbidity? Endokrynologia Polska 201768 524-532. (https://doi.org/10.5603/ EP.a2017.0044)

46 McCausland KL, White MK, Guthrie SD, Quock T, Finkel M, Lousada I \& Bayliss MS. Light chain (AL) amyloidosis: the journey to diagnosis. Patient 201811 207-216.

Received 21 November 2018

Revised version received 25 March 2019

Accepted 2 April 2019 